\title{
Characterization of medical ultrasound transducers
}

Tomov, Borislav Gueorguiev; Diederichsen, Søren Elmin; Thomsen, Erik Vilain; Jensen, Jørgen Arendt

Published in:

Proceedings of 2018 IEEE International Ultrasonics Symposium

Link to article, DOI:

10.1109/ULTSYM.2018.8579798

Publication date:

2018

Document Version

Peer reviewed version

Link back to DTU Orbit

Citation (APA):

Tomov, B. G., Diederichsen, S. E., Thomsen, E. V., \& Jensen, J. A. (2018). Characterization of medical ultrasound transducers. In Proceedings of 2018 IEEE International Ultrasonics Symposium [8579798] IEEE. https://doi.org/10.1109/ULTSYM.2018.8579798

\section{General rights}

Copyright and moral rights for the publications made accessible in the public portal are retained by the authors and/or other copyright owners and it is a condition of accessing publications that users recognise and abide by the legal requirements associated with these rights.

- Users may download and print one copy of any publication from the public portal for the purpose of private study or research.

- You may not further distribute the material or use it for any profit-making activity or commercial gain

- You may freely distribute the URL identifying the publication in the public portal 


\title{
Characterization of medical ultrasound transducers
}

\author{
Borislav Gueorguiev Tomov ${ }^{1}$, Søren Elmin Diederichsen ${ }^{2}$, Erik Thomsen ${ }^{2}$ and Jørgen Arendt Jensen ${ }^{1}$ \\ ${ }^{1}$ Center for Fast Ultrasound Imaging, Dept. of Elec. Eng. Bldg. 349, \\ Technical University of Denmark, DK-2800 Lyngby, Denmark \\ ${ }^{2}$ Dept. of Micro- and Nanotechnology, \\ Technical University of Denmark, DK-2800 Lyngby, Denmark
}

\begin{abstract}
Optimal use of multi-element ultrasound transducers requires knowledge of the performance of their individual elements, for realistic simulation and optimized beamforming. When developing transducers, it is critical to characterize the performance of the transducer material itself, removing the effect of the transducer element size and geometry. To provide that level of knowledge, a measurement and characterization algorithm was developed and applied on several transducers. The individual elements were characterized consistently along the transducer length, and element spatial deviations were measured with $\mu \mathrm{m}$ precision, confirming the precision of the method.
\end{abstract}

\section{INTRODUCTION}

Optimal use of medical ultrasound transducers requires complete information about the performance of their individual elements. A correctly measured impulse response allows for informed choice of excitation pulse for conventional and harmonic imaging, while individual corrections for element transmit delay and amplitude deviations contribute to improved focusing and image quality. Characterizing the individual elements of a transducer allows for better prediction of its performance, through incorporating the element-specific data in the simulation.

The transducer characterization has historically been performed by dedicated pulsers, emitting extremely short pulse [1]-[5], discrete frequency tones [6], [7] or linear frequency sweeps [8], [9]. In all of these cases, it has been assumed that the transducer elements are identical. In recent times, the advent of programmable research scanners with flexible transmit and receive logic allows transducer characterization to be performed almost automatically, on the same machine that will later use that transducer for medical imaging. For example, in [10], an ultrasound signal is generated photoacoustically (by short and powerful laser illumination), and the spectra of the received signals by a hydrophone and a transducer in its place are subtracted to yield the transducer receive impulse response. The transducers elevation focus is ignored, and it is assumed that all transducer elements have identical performance.

The current paper presents an approach for measuring the impulse response of individual transducer elements. Out of the obtained set of element impulse responses, individual deviations in response time/delay and amplitude are calculated, and the average impulse response of the transducer is derived. The results of the characterization of a number of piezo transducers (PZT) and an experimental capacitive micromachined ultrasound transducer (CMUT) are presented.

\section{MeAsurement METHOD}

A method for estimating the impulse response of an individual transducer elements was suggested in [11]. It requires that the hydrophone is located in the elevation focus of a transducer, exactly under the investigated element. To achieve that, the orientation of the transducer has to be found with high precision.

The Acoustic Intensity Measurement System AIMS III (Onda Corporation, Sunnyvale, USA) was used for the measurements. The control software for it was developed locally. The transducers under test were clamped by 3D-printed 2piece plastic adapters, made using the transducers CAD models (Fig. 1), and were fixed above the movable hydrophone in the AIMS water tank (Fig. 2). The fixation provides repeatability, but any positioning has a degree of imperfection that should be compensated for. The orientation relative to the axes of hydrophone movement in AIMS is determined through an alignment procedure, and the measurements are performed in the transducer-based coordinate system.

\section{A. Alignment routine}

The use of the experimental scanner SARUS [12] allows to devise an alignment routine in which focused beams are produced, at first, by an aperture at the center of the transducer, and then at each of its edges. The hydrophone is used for estimating the origins and the directions of these beams. Based on that, the transducer unit vector relative to the AIMS coordinate system is determined. Hereby, the transducer-centric coordinate system is established reliably, even in the presence

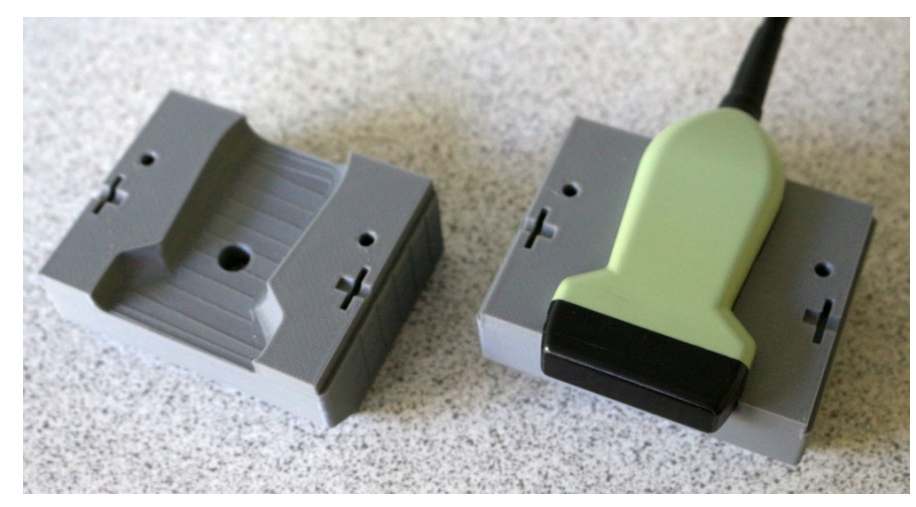

Fig. 1. A 3D-printed adapter for transducer, which ensures repeatable and reliable positioning of a transducer. 


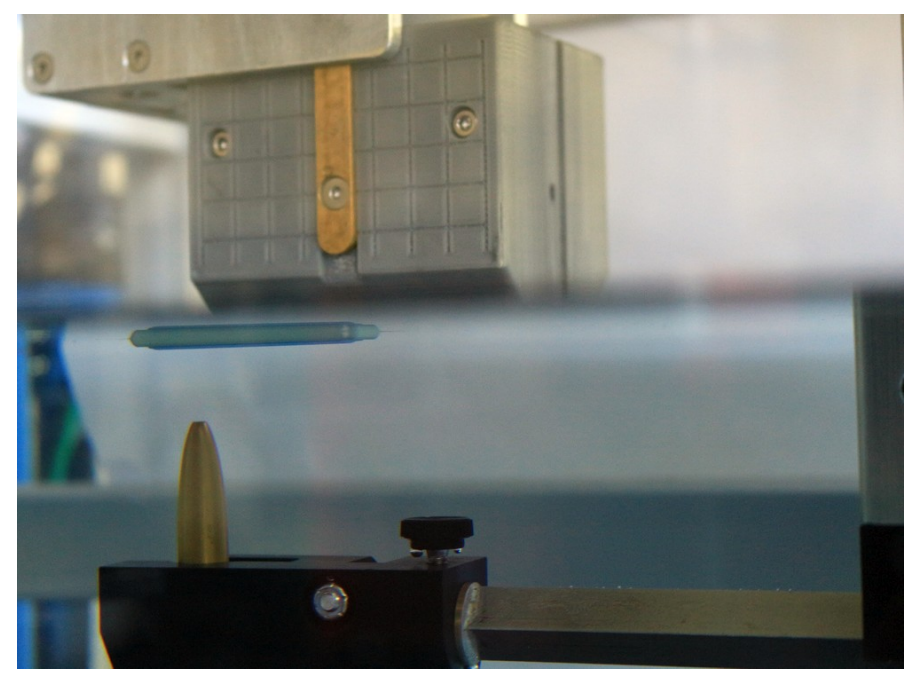

Fig. 2. A photo of the measurement setup, where the transducer is fixed in its adapter and suspended above the hydrophone. The visual mismatch is due to the fact that the camera is pointed obliquely to the water tank wall.

of weak/defective transducer elements that distort the beam patterns.

\section{B. Transmit impulse response}

The method for estimating the impulse response of an individual transducer has been published previously in [11]. Here, a summary of it is presented.

The hydrophone signal can be described as:

$$
p(t, r)=\rho \cdot e(t) * \frac{d V(t)}{d t} * h_{t e}(t) * h(t, \vec{r}),
$$

where $\rho$ is the water density, $e(t)$ is the excitation signal, $d V(t) / d t$ is the transducer impulse response in transmit, $h_{t e}$ is the electrical impulse response of the transmit amplifier, and $h(t, \vec{r})$ is the transducer-hydrophone spatial impulse response.

The amplifiers frequency response is much broader than that of the transducer under test, so it is assumed flat in the frequency range of the transducer.

$h(t, \vec{r})$ is calculated in Field II [13], [14] from the geometry of the transducer elements and their spatial relationship with the hydrophone.

The excitation signal $e(t)$ is chosen to be a stochastic white random signal (constant spectral density) with discrete representation $e(n)$, whose auto-correlation is

$$
\gamma_{x x}(m)=P_{e} \delta(m),
$$

where $P_{e}$ is the power of the discrete signal [15]. In this way, when the excitation signal is emitted through a transducer and the recorded pressure waveform is correlated with it, that yields (ideally) a scaled version of the transmit impulse response. The realization of the stochastic signal is finite (an excitation waveform of 700 samples), so the result of the autocorrelation is not only a delta function, but also includes artifacts. For reducing the error in this process and improving the signal-to-noise ratio, it is repeated 50 times with different stochastic signals as excitations, and the element impulse response is the mean of the 50 estimates.

The purpose of these calculations is to derive an impulse response curve in $\mathrm{Pa} / \mathrm{Vs}^{2}$ for the transducer that is independent of area and is only a property of the transducer material. That electro-mechanical impulse response can later be used for arbitrary transducer geometries of the same material for predicting the emitted field and the imaging performance.

\section{Element inclusion criteria}

After the individual impulse responses of the transducer elements have been estimated, they are evaluated with respect to uniformity. Two parameters are inspected: relative time delay of the signal arrival at the hydrophone, and the relative amplitude of the impulse response. An initial mean impulse response is created by averaging across the elements. The relative time delays are obtained by finding the lag of the peak cross-correlation between each impulse response and the mean one. For any relative time delay that differs too much (more than time corresponding to $\lambda / 2$ ) from its neighbors, the corresponding element is marked as malfunctioning. Elements with impulse response amplitude smaller than 0.6 of the average are also marked as malfunctioning. The remaining acceptable impulse responses are aligned in time and averaged to produce impulse response of the transducer, and statistics is done on them and their spectra.

\section{Pulse-echo impulse response}

The pulse-echo response, measured with the help of a reflecting surface, can be described mathematically as:

$$
\begin{aligned}
s(t, r)= & \rho \cdot e(t) * \frac{d V(t)}{d t} * h_{t e}(t) * h_{t}(t, \vec{r}) \cdot k_{r} \\
& * h_{r}(t, \vec{r}) * \frac{d V_{r}(t)}{d t} * H_{r e}(t),
\end{aligned}
$$

where the first four terms are as in Eq.1, $h_{t}$ and $h_{r}$ are the transmit and receive spatial impulse responses, $k_{r}$ is the reflection coefficient and was calculated to be 0.16 for a sound wave in water, $d V_{r}(t) / d t$ is the transducer receive impulse response, and $H_{r e}$ is the receive amplifier impulse response. Here, both amplifier impulse responses (Tx and Rx) are assumed to be delta functions.

For evaluating the pulse-echo impulse response, a Plexiglas plate is placed under the transducer in the AIMS water tank, parallel to the transducer surface. The emit/receive is done using a single element at a time, again with 50 different stochastic signal emissions per element. The plate was placed at the elevation focus depth for the transducer. The distance to the plate was measured by emitting a plane wave by the center 4 elements of the transducer, and measuring the arrival time of the reflected wave. Interactive corrections were done by the operator until the echo arrival time corresponded to the elevation focus depth. The Plexiglas plate tilt was compensated for after estimating the individual element impulse responses. 


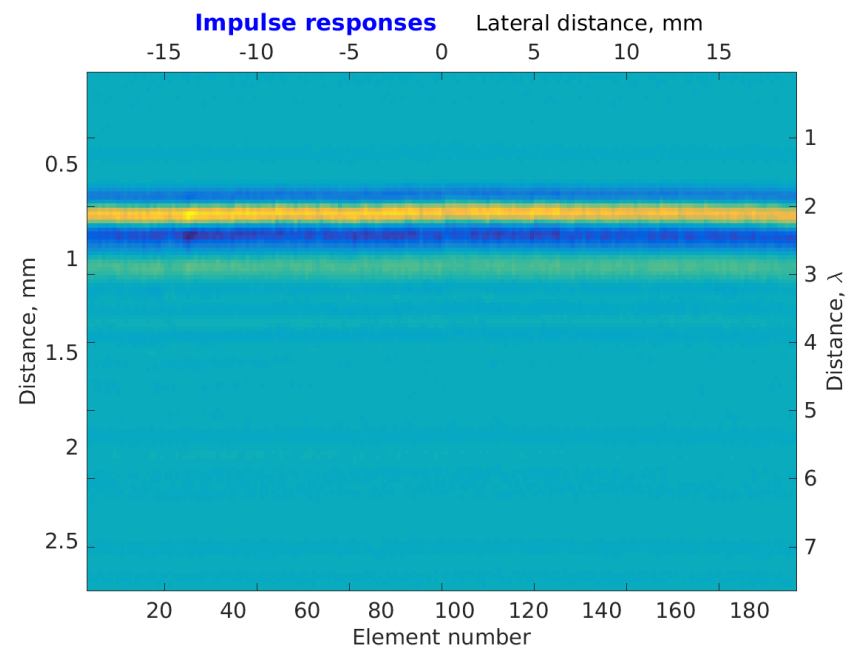

Fig. 3. The transmit impulse responses by element. Each element trace is an average of 50 emissions/estimations.

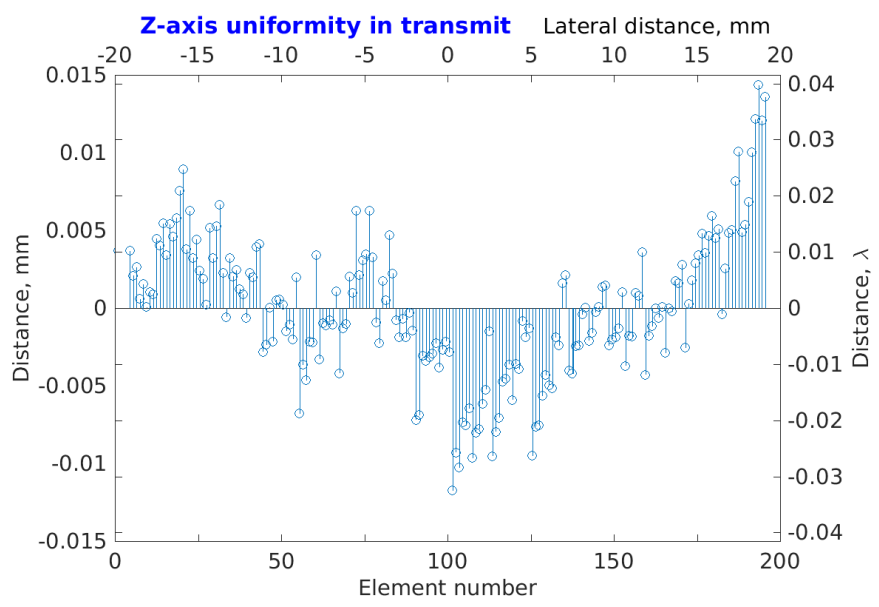

Fig. 4. Z-axis uniformity in transmit (hydrophone signal relative delays).

The pulse-echo sensitivity is expressed in units of V/V and is the ratio of measured echo signal (in Volts) relative to the expected echo signal, calculated as the excitation voltage reduced two times by the propagation attenuation (forward and back) and the reflection coefficient of the plate.

\section{RESULTS}

The individual element impulse responses for a transducer (Linear PZT 5 in in Table I) are shown in Fig. 3.

Based on the average impulse response, the relative signal delays per element are calculated (Fig. 4). These reflect the relative delay between the pressure wave arrival times at the hydrophone.

The strength of each element impulse response relative to the average impulse response is calculated (Fig. 5).

The stability of the arrival times and the amplitudes confirms, first, that this transducer has good uniformity, and

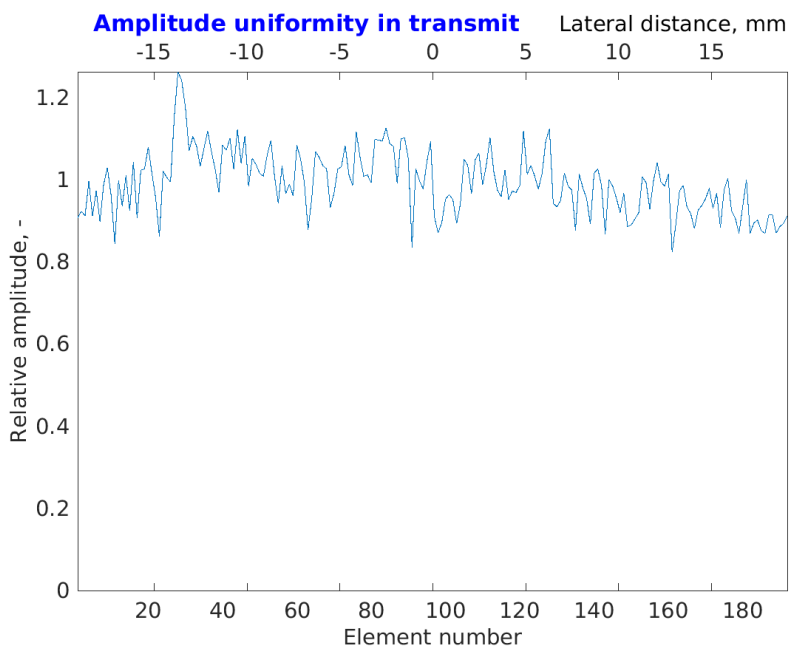

Fig. 5. Amplitude uniformity relative to the average.
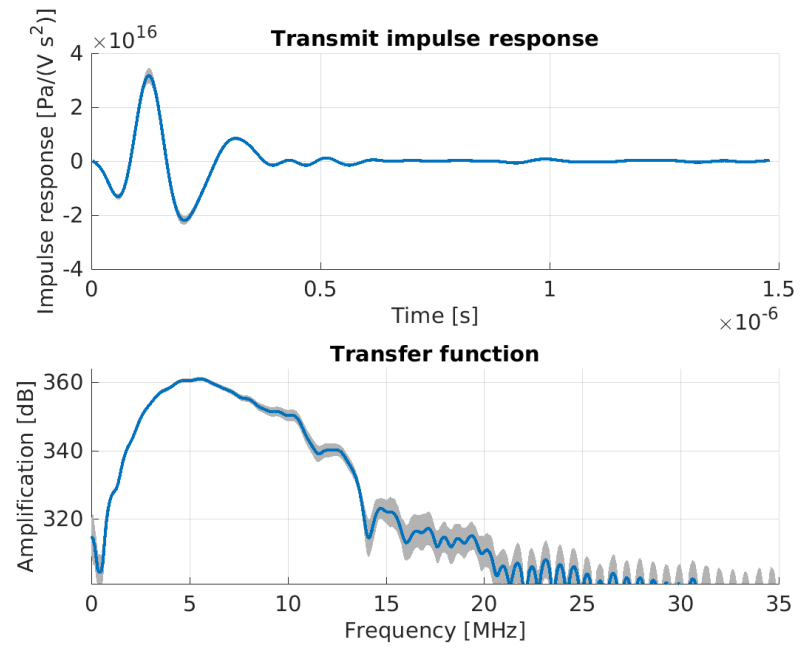

Fig. 6. Transmit impulse response estimate in the time (top) and the frequency (bottom) domains. The gray area in both plots shows the standard deviation among the acceptable elements.

second, that the placement of the hydrophone was precise, i.e. staying within the elevation focus zone from one end of the transducer to the other.

After removing the failing element responses (there are none in this particular transducer), the transmit impulse response of the transducer is produced (Fig. 6).

The same exclusion and estimation procedure is performed for the pulse-echo impulse response, with the addition of a tilt compensation. The resulting pulse-echo impulse response for the same transducer is shown in Fig. 7.

The main impulse response parameters for a number of commercial transducers and an experimental CMUT are presented in Table I. The latter has exactly the same element geometry as PZT 5. In that pair, the CMUT has much lower transmit sensitivity, but the pulse-echo sensitivity is the same because of the better CMUT receive sensitivity. 


\begin{tabular}{|l|c|c|c|c|c|c|c|c|}
\hline Transducer type, $\mathrm{f}_{0}$ & $\begin{array}{c}\text { Tx sens. } \\
{\mathrm{Pa} / \mathrm{Vs}^{2}}^{2}\end{array}$ & $\begin{array}{c}\text { Tx rel. BW } \\
\%\end{array}$ & $\begin{array}{c}\text { Z-axis std. } \\
\mu \mathrm{m}\end{array}$ & $\begin{array}{c}\text { Ampl. std. } \\
\%\end{array}$ & $\begin{array}{c}\text { Pulse-echo sens. } \\
\mathrm{mV} / \mathrm{V}\end{array}$ & $\begin{array}{c}\text { Pulse-echo rel. BW } \\
\%\end{array}$ & $\begin{array}{c}\text { Z-axis std. } \\
\mu \mathrm{m}\end{array}$ & $\begin{array}{c}\text { Ampl. std. } \\
\%\end{array}$ \\
\hline Linear PZT 1, 8 MHz & $7.88 .10^{16}$ & 87 & 3.1 & 7.0 & 16.2 & 95 & 6.1 & 5.3 \\
Linear PZT 2, 10 MHz & $1.10 .10^{17}$ & 89 & 7.6 & 14.3 & 17.5 & 93 & 10.1 \\
Linear PZT 3, 5.5 MHz & $2.81 .10^{16}$ & 86 & 9.2 & 6.9 & 22.7 & 12.1 \\
Linear PZT 4, 11 MHz & $8.85 .10^{16}$ & 112 & 10.2 & 29.8 & 10.6 & 101 & 10.5 \\
Linear PZT 5, 4.8 MHz & $3.17 .10^{16}$ & 86 & 4.5 & 7.6 & 14.1 & 101.3 & 16.8 \\
Linear CMUT, 4.8 MHz & $4.99 .10^{15}$ & 101.1 & 75.0 & 28.3 & 14.1 & 81.5 & 11.8 \\
\hline
\end{tabular}

TABLE I

PERFORMANCE AND STATISTIC PARAMETERS OF TESTED TRANSDUCERS

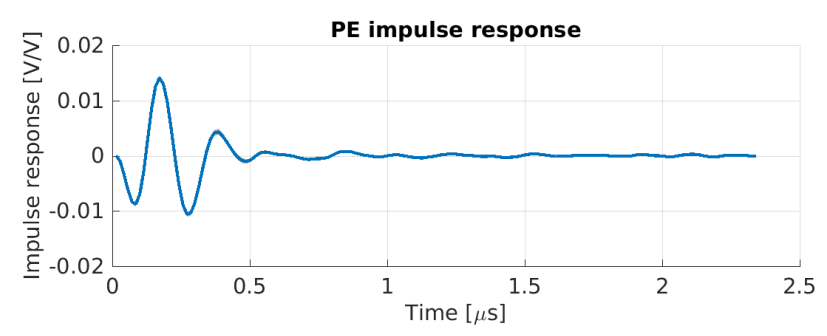

Two-way transfer function

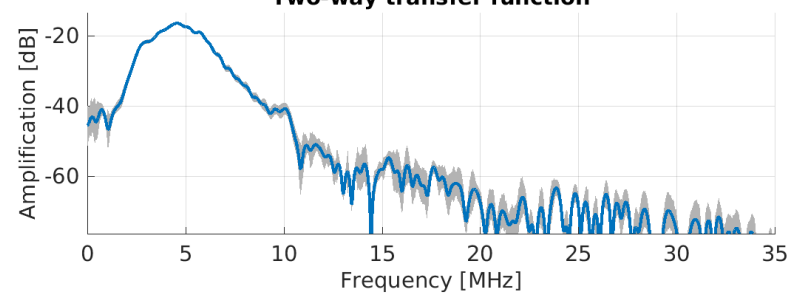

Fig. 7. The pulse-echo impulse response estimate. The gray area shows the standard deviation among the acceptable elements.

\section{DISCUSSION}

Although the speed of sound in Plexiglas is known and the reflection coefficient can be estimated, the reflecting area is not known, therefore the amplitude of expected received signal can not be calculated correctly, only the shape of it. Nevertheless, the relative receive sensitivity advantages between transducers can be estimated, if they have the same element geometry, acoustical lens and elevation focal depth. This is the case for the CMUT and PZT 5 in Table I.

\section{CONCLUSION}

Knowledge about the performance of the individual transducer elements is needed for compensating for imperfections, accurate simulation or evaluation of experimental transducers. The suggested method reveals the performance of the individual transducer elements with high precision, allowing comparisons between transducers and between transducer technologies. It detects minute manufacturing defects with $\mu \mathrm{m}$ precision and provides data for compensation, enabling high quality beamforming and precise simulation.

\section{ACKNOWLEDGMENT}

This work was supported by the Danish National Advanced Technology Foundation (82-2012-4), Innovation Fund Den- mark (7050-00004B) and by BK Medical, Herlev, Denmark

\section{REFERENCES}

[1] R. L. Tutwiler, S. Madhavan, and K. V. Mahajan, "Design of test system to characterize very high frequency ultrasound transducer arrays," in Proc. SPIE Med. Imag., vol. 3664, 1999, pp. 182-193. [Online]. Available: https://doi.org/10.1117/12.350674

[2] O. Clade, N. Felix, and E. Lacaze, "Linear and curved array with advanced electroacoustic and acoustic properties," in Proc. IEEE Ultrason. Symp., vol. 2, Oct 2002, pp. 1127-1130.

[3] A. Caronti, G. Caliano, R. Carotenuto, A. Savoia, M. Pappalardo, E. Cianci, and V. Foglietti, "Capacitive micromachined ultrasonic transducer (CMUT) arrays for medical imaging," Microelectronics Journal, vol. 37, no. 8, pp. 770-777, aug 2006.

[4] L. Schmerr, A. Lopez-Sanchez, and R. Huang, "Complete ultrasonic transducer characterization and its use for models and measurements," in Ultrasonics, vol. 44, 2006, pp. 753-757.

[5] M. M. Hejazi, B. Jadidian, and A. Safari, "Fabrication and evaluation of a single-element $\mathrm{Bi}_{0.5} \mathrm{Na}_{0.5} \mathrm{TiO}_{3}$-based ultrasonic transducer," IEEE Trans. Ultrason., Ferroelec., Freq. Contr., vol. 59, no. 8, pp. 1840-1847, August 2012.

[6] K. Erikson, "Tone-burst testing of pulse-echo transducers," IEEE Trans. Son. Ultrason., vol. 26, no. 1, pp. 7-13, 1979.

[7] D. H. Turnbull and F. S. Foster, "Fabrication and characterization of transducer elements in two-dimensional arrays for medical ultrasound imaging," IEEE Trans. Ultrason., Ferroelec., Freq. Contr., vol. 39, no. 4, pp. 464-475, July 1992.

[8] P. A. Lewin, P. C. Pedersen, and M. E. Schafer, "A spectral analysis technique in ultrasound transducer characterization," in Proc. IEEE Ultrason. Symp., Nov 1984, pp. 731-734.

[9] R. C. Chivers, "Time-delay spectrometry for ultrasonic transducer characterization," J. Phys. E: Sci. Instrum., vol. 19, no. 10, pp. 834-843, 1986. [Online]. Available: http://stacks.iop.org/0022-3735/19/ $\mathrm{i}=10 / \mathrm{a}=015$

[10] M. Vallet, F. Varray, J. Boutet, J.-M. Dinten, G. Caliano, A. S. Savoia, and D. Vray, "Quantitative comparison of PZT and CMUT probes for photoacoustic imaging: Experimental validation," Photoacoustics, vol. 8, pp. 48-58, 2017.

[11] J. A. Jensen, "Safety assessment of advanced imaging sequences, II: Simulations," IEEE Trans. Ultrason., Ferroelec., Freq. Contr., vol. 63, no. 1, pp. 120-127, 2016.

[12] J. A. Jensen, H. Holten-Lund, R. T. Nilsson, M. Hansen, U. D. Larsen, R. P. Domsten, B. G. Tomov, M. B. Stuart, S. I. Nikolov, M. J. Pihl, Y. Du, J. H. Rasmussen, and M. F. Rasmussen, "Sarus: A synthetic aperture real-time ultrasound system," IEEE Trans. Ultrason., Ferroelec., Freq. Contr., vol. 60, no. 9, pp. 1838-1852, September 2013.

[13] J. A. Jensen and N. B. Svendsen, "Calculation of pressure fields from arbitrarily shaped, apodized, and excited ultrasound transducers," IEEE Trans. Ultrason., Ferroelec., Freq. Contr., vol. 39, pp. 262-267, 1992.

[14] J. A. Jensen, "Field: A program for simulating ultrasound systems," Med. Biol. Eng. Comp., vol. 10th Nordic-Baltic Conference on Biomedical Imaging, Vol. 4, Supplement 1, Part 1, pp. 351-353, 1996.

[15] J. M. Blackledge, Digital Image Processing, ser. Woodhead Publishing Series in Electronic and Optical Materials. Woodhead Publishing, 2005, ch. Ch. 17 , pp. 512-540. 